\title{
Neuroprotective effects of Lippia javanica (Burm.F.) Spreng. Herbal tea infusion on Lead- induced oxidative brain damage in Wistar rats
}

Zubair Suleman ${ }^{1}$, Godwill A. Engwa ${ }^{2}$, Mathulo Shauli ${ }^{1}$, Hannibal T. Musarurwa', Ndinashe A. Katuruza ${ }^{1}$ and Constance R. Sewani-Rusike ${ }^{1^{*}}$

\begin{abstract}
Background: Though Lippia javanica (Burm.f.) Spreng antioxidant activity has been demonstrated, its effect in protecting the brain from lead (Pb)-induced oxidative damage is unknown. This study investigated the effect of $L$. javanica against $\mathrm{Pb}$-induced oxidative stress, inflammation, apoptosis and acetylcholinesterase activity in rat's brain.

Methods: L. javanica herbal tea infusion was prepared, its phytochemical constituent was revealed by liquid chromatography-Mass spectrometer (LC-MS) and was administered simultaneously with Pb. Four groups of male Wistar rats ( $n=5 /$ group) were used: control received distilled water; Pb-acetate group received $50 \mathrm{mg} \mathrm{Pb} / \mathrm{Kg}$ bodyweight (bw), treatment group received $50 \mathrm{mg} \mathrm{Pb} / \mathrm{Kg} \mathrm{Pb}$-acetate $+5 \mathrm{ml} / \mathrm{kg}$ bw L. javanica and L. javanica group received $5 \mathrm{ml} / \mathrm{Kg}$ bw of L. javanica tea infusion only. After 6 weeks of treatment, oxidative status, acetylcholinesterase activity, inflammation and apoptosis was assessed in brain tissue which was also histologically examined.
\end{abstract}

Results: Mean brain and heart weight was reduced $(p<0.05)$ while liver and spleen weights were increased $(p<0.05)$ in Pb exposed animals but were prevented by L. juvanica treatment. Treatment with L. javanica increased $(p<0.05)$ overall brain antioxidant status (glutathione and superoxide dismutase activities) and reduced lipid peroxidation $(p<0.05)$ compared to the $\mathrm{Pb}$ exposed animals. Pro-inflammatory cytokine tumour necrotic factor-alpha, pro-apoptosis Bax protein and anticholinesterase activity were reduced $(p<0.05)$ in Pb-L. javanica treated animals compared to the $\mathrm{Pb}$ exposed group. Histological examination confirmed neuroprotective effects of $L$. javanica as evidenced by reduced apoptosis/necrosis and inflammation-induced vacuolization and oedema in the hippocampus. The L. javanica treatment alone had no detrimental effects to the rats. LC-MS analysis revealed L. javanica to be rich in phenolics. Conclusions: This study demonstrated that L. javanica, rich in phenolics was effective in reducing Pb-induced brain oxidative stress, inflammation, apoptosis, acetylcholinesterase activity and neuronal damage.

Keywords: Lead, Oxidative stress, Inflammation, Apoptosis, Neuronal damage, Polyphenols

*Correspondence: crusike@wsu.ac.za

${ }^{1}$ Department of Human Biology, Faculty of Health Sciences, Walter Sisulu University PBX1, Mthatha 5117, South Africa

Full list of author information is available at the end of the article

\section{Introduction}

Lead $(\mathrm{Pb})$ is a toxic heavy metal widely distributed across environments all around the world with no beneficial roles in biological systems [1]. Exposure to $\mathrm{Pb}$ has been a problem of global concern for decades especially in children [2]. $\mathrm{Pb}$ poisoning is known to alter the body function as it can affect the hematologic, hepatic, cardiovascular, reproductive, gastrointestinal and neurological 
systems in the body [3]. As such, $\mathrm{Pb}$ has been reported to affect speech, nerve conduction and hearing, as well as cause weight loss, hyperactivity, intestinal discomfort, vomiting, constipation, and muscle aches. $\mathrm{Pb}$ poisoning can equally lead to anemia, paralysis, nephropathy, convulsions or death [4]. In pregnancy, $\mathrm{Pb}$ can affect the foetus causing intrauterine deaths, miscarriages and/or low birth weight [5].

Neurological damage induced by $\mathrm{Pb}$ toxicity is reported to be a base for multiple disorders such as Parkinson's and Alzheimer's diseases [6]. Pb has the ability to pass through the blood-brain barrier due to its calcium ionsubstituting ability to damage the prefrontal cortex, cerebellum and hippocampus [7]. The disruption of the brain barrier by $\mathrm{Pb}$ causes albumin to enter the tissues of the central nervous system (CNS), resulting in increased intracranial pressure, edema, and encephalopathy [8]. $\mathrm{Pb}$ exposure in the brain affects neurotransmitters including cholinergic, dopaminergic and glutaminergic systems [9]. One of the characteristic features of $\mathrm{Pb}$ intoxication in the brain is impairment of the action of acetylcholinesterase (AChE) in cholinergic nerve cells transmission [10]. The central cholinergic system is essential for the regulation of cognitive functions. As such, cholinergic receptor agonists and inhibitors of $\mathrm{AChE}$ are used to control endogenous acetylcholine levels to overcome cognitive deficits [11].

$\mathrm{Pb}$ neurotoxicity also promotes pro-inflammatory effects in the brain. $\mathrm{Pb}$ is known to induce increase gene expression and secretion of interleukin 6 (IL-6), tumour necrotic factor- $\alpha$ (TNF- $\alpha$ ) and transforming growth factor $\beta 1$ (TGF- $\beta 1$ ) leading to increased inflammation in the brain [11]. Inflammatory processes have been observed in the pathogenesis of Parkinson's, Alzheimer's diseases and in multiple sclerosis [12]. Also, Pb toxicity is known to cause apoptotic neurodegeneration [13]. Studies have shown $\mathrm{Pb}$ to increase mRNA and protein levels of apoptotic factors including caspase and $\mathrm{Bcl}-2$ Associated $\mathrm{X}$ Protein (Bax), evidence that $\mathrm{Pb}$ increases neurodegeneration [14].

$\mathrm{Pb}$ toxicity induces oxidative stress by generating reactive oxygen species (ROS) such as superoxide $\left(\mathrm{O}^{2-}\right)$, hydroperoxides $\left(\mathrm{HO}_{2}{ }^{\circ}\right)$ and hydrogen peroxide $\left(\mathrm{H}_{2} \mathrm{O}_{2}\right)$, as well as by depleting the antioxidant defence systems [15]. Glutathione (GSH) is an important antioxidant that directly or indirectly scavenges ROS. Also, antioxidant enzymes including superoxide dismutase (SOD) and catalase (CAT) are important ROS scavengers. However, these enzymes can be rendered inactive or reduced by $\mathrm{Pb}$ [15]. Failure of the body to meet the homeostatic requirement due to overwhelming ROS level results in the occurrence of oxidative stress characterised by oxidative damage of proteins, nucleic acid and membrane lipids (lipid peroxidation) [16]. Cellular by-products of oxidative damage also stimulate inflammation and cell death.

In recent years, studies conducted on the use of antioxidants as an intervention for $\mathrm{Pb}$-induced neurotoxicity and oxidative stress has shown success. Gallic acid, a phenolic compound of natural origin attenuated locomotor damage and brain oxidative stress induced by $\mathrm{Pb}$ exposure [17]. Also, geinstein was shown to alleviate $\mathrm{Pb}$-induced neurotoxicity through the involvement of multiple signalling pathways in vitro and in vivo [18]. Plants rich in phenolic compounds are known to play an important role as antioxidants which enhances their medicinal properties. One of such plant is Lippia javanica (Burm.f.) Spreng. which has been shown to possess antioxidant activities in in-vitro studies [19-21]. Traditionally, parts of $L$. javanica have been used medicinally for the treatment of respiratory ailments such as colds, coughs, asthma and tuberculosis [22]. It has also been reported in the treatment of gastrointestinal tract disorders such as abdominal pain [23] which is a common symptom of $\mathrm{Pb}$ poisoning. Although L. javanica has been shown to possess higher antioxidant capacity as well as better free radical scavenging activity than a known antioxidant, rooibos (Aspalathus linearis) in vitro [24], it remains unknown whether the in vitro antioxidant properties of $L$. javanica can translate to in vivo neuroprotective effects of $\mathrm{Pb}$-induced toxicity against oxidative stress, inflammation, apoptosis and acetylcholinesterase activity. Therefore, the aim of this study was to investigate the effectiveness of L. javanica in attenuating $\mathrm{Pb}$-induced toxicity in rat's brain.

\section{Materials and methods \\ Preparation of tea infusion}

The Lippia javanica (Burm.f.) Spreng. herbal tea was purchased from Harare, Zimbabwe. One hundred millilitres $(100 \mathrm{ml})$ of boiled deionised water was added to $5 \mathrm{~g}$ of dry L. javanica leaves followed by stirring with a magnetic stirrer for $10 \mathrm{~min}$ then steeping for $30 \mathrm{~min}$ and strained with a fine mesh tea strainer followed by vacuum filtration through Whatman No. 1 filter paper [25]. The tea infusion was prepared weekly and used for animal treatments.

\section{Experimental animals and ethics statement}

All methods were performed in accordance with the study protocol of relevant institutional, national, and international guidelines, regulations and legislation required for plants and animal studies. This study was conducted in accordance with the ethical guidelines of Animal Care and Use and the Animal Research: Reporting of In Vivo Experiments (ARRIVE) guidelines. Ethical clearance with approval number: [060/2016] was 
obtained from the Faculty of Health Sciences, Walter Sisulu University ethical committee on the 14th of November 2016 before commencement of study. Twenty (20) Wistar, adult male rats $(270 \mathrm{~g}-340 \mathrm{~g})$ which were 10 weeks old were procured from South African Vaccine Producers (Johannesburg, South Africa) and housed in a temperature-controlled $\left(20^{\circ} \mathrm{C}-24^{\circ} \mathrm{C}\right)$ animal house in plastic cages with open, steel tops, with each cage housing 5 rats. The rats had free access to rat pellet feed (Epol, SA) and tap water which was topped up twice daily to ensure constant availability. The cages were cleaned and new bedding was added twice a week. The general health status of the rats was observed daily before and after treatment and their body weights was measured and recorded once every 2 weeks. The rats were handled in a humane manner in keeping with the guidelines as specified by the National Council of the Society for the Prevention of Cruelty to Animals (SPCA) and the South African National Standard: The care and use of animals for scientific purposes (2008) [26]. The rats were euthanized humanely by $\mathrm{CO}_{2}$ inhalation.

\section{Animal treatments}

Male Wistar rats were divided into 4 treatment groups of 5 rats per group. All treatments were administered by oral gavage using a rat feeding needle (18G) attached to a $5 \mathrm{ml}$ syringe. Treatments were given for 5 consecutive days per week for a total of 6 weeks. The experimental groups were:

1. Control group: $1 \mathrm{ml}$ of distilled water

2. Pb-acetate only: $50 \mathrm{mg}$ of lead acetate per kg bodyweight (bw) in $1 \mathrm{ml}$ volume.

3. $\mathrm{Pb}$-acetate + L. javanica: $50 \mathrm{mg} / \mathrm{kg}$ bw of lead acetate and $5 \mathrm{ml} / \mathrm{Kg}$ bw L. javanica tea infusion each in $1 \mathrm{ml}$ volume.

4. L. javanica only: $5 \mathrm{ml} / \mathrm{kg}$ bw of $L$. javanica tea infusion in $1 \mathrm{ml}$ volume

$\mathrm{Pb}$-acetate dosage was selected based on a previous study [27] which is equivalent to $32 \mathrm{mg} / \mathrm{kg} \mathrm{Pb}$, below the rat oral $\mathrm{LD}_{50}$ of $56 \mathrm{mg} / \mathrm{kg}$ [28], while the dosage for $L$. javanica is 1 cup human dose equivalent as reported previously for rooibos tea [29].

\section{Terminal procedures}

At the end of the 6-week treatment period, all the rats were terminated by $\mathrm{CO}_{2}$ inhalation. Vital organs (heart, liver, kidneys and spleen) were harvested, cleaned of excess adhering tissue, weighed and percentage of body weight calculated (Organ weight index) for comparison across treatment groups. The brains were removed by partial decapitation, weighed and then halved medially.
Half of the brain was immediately frozen at $-70^{\circ} \mathrm{C}$ (Skadi Green Line Ultra-Low freezer, UK) for homogenization and biochemical analyses. The other half brain tissue was fixed in 10\% buffered formalin (Associated Chemical Enterprises, Johannesburg, South Africa) for histology.

\section{Tissue homogenization}

Brain tissue $(0.2-0.4 \mathrm{~g})$ was thawed and homogenized in $0.01 \mathrm{M}$ phosphate buffered saline, pH7.4 (PBS; Sigma Aldrich, USA) to attain a concentration of $1: 10(\mathrm{w} / \mathrm{v})$ using Potter-Elvehjem glass tissue homogenizer. The resultant homogenates were placed in glass test tubes on ice and centrifuged for $10 \mathrm{~min}$ at $3000 \mathrm{rpm}$ at $4{ }^{\circ} \mathrm{C}$ (Eppendorf $5810 \mathrm{R}$, Germany) and the resultant supernatants were collected in Eppendorf microtubes for biochemical analysis.

\section{Biochemical assays Total antioxidant capacity}

Trolox equivalent antioxidant capacity (TEAC) assay was used to measure the total antioxidant capacity (TAC) in the brain tissue samples reflective of radical scavenging activity of antioxidants according to the method of Arnao and colleagues [30]. In this assay, the antioxidant capacity of a sample was determined based on the antioxidant reaction that reduces the blue $\mathrm{ABTS}^{\cdot+}$ radical to its neutral, colourless form, ABTS (2, 2'-azino-bis-(3-ethylbenzthiazoline-6-sulphonic acid). Trolox (6-hydroxy-2, 5, 7, 8-tetramethylchroman-2-carboxylic acid) was used for construction of the standard curve. Absorbance was read at $734 \mathrm{~nm}$ in a spectrophotometer (Phoenix-2000 V UVVIS, Biotech Engineering Management Co. Ltd. (UK)). The assay was run on $50 \mu \mathrm{l}$ of brain tissue homogenate in duplicate. TAC of the sample was calculated using the linear equation from the standard curve and were expressed as $\mathrm{mg} / \mathrm{ml}$ Trolox equivalent (TE).

\section{Determination of reduced glutathione concentration}

Reduced glutathione (GSH) was determined as previously reported by Owens and Belcher [31]. The assay utilised Ellman's reagent (5, 5 dithiobis 2-nitrobenzoic acid) which reacts with reduced GSH resulting in a yellow colour chromophore, 5 - thionitrobenzoic acid (TNB) with intensity proportionate to the GSH concentration in samples and standards, read at $415 \mathrm{~nm}$. The GSH concentration of samples was calculated using the linear equation from the standard curve and expressed in $\mu \mathrm{Mol}$ $\mathrm{GSH} / \mathrm{g}$ tissue.

\section{Superoxide dismutase activity}

Superoxide dismutase (SOD) activity in brain tissue samples was measured using a commercial assay kit (Cayman, Ann Arbor, USA) as per manufacturer's 
instructions. SOD activity of the samples was calculated using the linear equation from the standard curve and expressed in $\mathrm{U} / \mathrm{mL}$.

\section{Lipid peroxidation}

The lipid peroxidation of the homogenised brain tissue samples was determined by the TBARS (thiobarbituric acid reactive substances) assay according to the method of Mallick and colleagues [32]. The principle of this assay relies on the reaction of 2-thiobarbituric acid with malondialdehyde (MDA), a product and marker of lipid peroxidation, at $100^{\circ} \mathrm{C}$ to yield a pink chromophore whose absorbance was read at $532 \mathrm{~nm}$ in a spectrophotometer (Phoenix-2000 V UV-VIS, Biotech Engineering Management Co. Ltd. (UK)). The MDA concentration was calculated using molar extinction coefficient of MDA and expressed in $\mu \mathrm{M}$.

\section{Determination of acetylcholinesterase activity}

The acetylcholinesterase (AChE) activity was determined using the colorimetric assay as previously described by Ellman and colleagues [33]. Briefly, brain homogenate was mixed with Ellman's reagent (5,5'-dithio-2-nitrobenzoic acid) followed by the addition of the enzyme substrate, acetylthiocholine. The yellow colour change in absorbance/min during a 5 min interval was measured at $405 \mathrm{~nm}$ in a microplate reader (BioRad, CA, USA). The change in absorbance/min was expressed as enzyme activity in $\mu$ moles of acetylthiocholine hydrolyzed/ $\mathrm{min} /$ gram of wet brain tissue ( $\mu$ moles $/ \mathrm{min} / \mathrm{g}$ tissue).

\section{Quantification of tumour necrosis factor-alpha (TNF-a) and Bax protein}

The pro-inflammatory cytokine TNF- $\alpha(\mathrm{pg} / \mathrm{ml})$ and proapoptosis protein $\mathrm{Bax}(\mathrm{ng} / \mathrm{ml})$ were measured using commercial enzyme-linked immunosorbent assay (ELISA) kits (Elabscience ${ }^{\circledR}$ USA catalogue E-EL-R0019 and E-EL-R0098 respectively) according to manufacturers' protocol.

\section{Histology}

Brain tissue fixed in 10\% buffered formalin was subjected to standard procedures for fixing, washing, dehydration and paraffin embedding as previously described by us [34]. Following fixing of the brain tissue, $5-\mu \mathrm{m}$ sections were cut and mounted on clean slides. Slides were stained with haematoxylin and counterstained with eosin for light microscopic examination. Images were taken using a digital Leica DMD108 microscope (Wetzlar, Germany).

\section{Liquid chromatography-mass spectrometer analysis} of Lippia javanica

Leaves of $L$. javanica were dried at room temperature and ground with a pestle in a mortar into powder. The dried leaf powder $(2 \mathrm{~g})$ was soaked overnight with $15 \mathrm{~mL}$ of $50 \%$ methanol in deionised water containing $1 \%$ formic acid. It was then extracted in an ultrasonic bath $(0.5 \mathrm{~Hz}$, Integral Systems, RSA) for $60 \mathrm{~min}$ at room temperature and centrifuged (Hermle $\mathrm{Z} 160 \mathrm{~m}$,) at $3000 \mathrm{~g}$ for $5 \mathrm{~min}$. The supernatant was transferred into vials for LC-MS analysis. The extract was analysed in an ultra-performance liquid chromatography (UPLC) (Waters, Milford, MA, USA) connected to a Waters Synapt G2 Quadrupole time-of-flight (QTOF) mass spectrometer (MS) as previously reported by us [35]. Polyalanine was used for calibration and calculations according to Rautenbach et al. [36]. Samples were run in triplicate and results presented as relative abundance (\%).

\section{Statistical analysis}

Data was analysed using GraphPad Prism Version 5 statistical package and presented as mean \pm standard error of the mean (SEM) in tables and figures. One-way analysis of variance (ANOVA) was used to compare means between groups followed by Tukey's multiplecomparison test. A $p \leq 0.05$ was considered statistically significant.

\section{Results}

\section{Effect of Lippia javanica on organ weights}

All organ weights were expressed as percent of body weight. $\mathrm{Pb}$ treatment resulted in increased liver and spleen weight indices $(p<0.05)$ and reduced heart and brain weight indices $(p<0.05)$ compared to the controls. These $\mathrm{Pb}$ associated detrimental effects on liver, heart, spleen and brain were prevented by treatment with $L$. javanica except the kidney which was increased compared to controls. Treatment with $L$. javanica alone had no effect on organ weights (Table 1 ).

\section{Effects of Lippia javanica on brain antioxidant status}

The non-enzymatic total antioxidant capacity was simi$\operatorname{lar}(p>0.05)$ across all treatment groups. However, $\mathrm{Pb}$ exposure resulted in depletion of GSH $(p<0.05)$ compared to control and treatment with $L$. javanica, with and without $\mathrm{Pb}$ resulted in increased GSH $(p<0.05$; $p<0.01)$ compared to the $\mathrm{Pb}$ group. For enzymatic antioxidant SOD, all groups exhibited increased SOD activity $(p<0.05)$ compared to control. The $\mathrm{Pb}$ exposed group had higher lipid peroxidation as shown by the higher MDA concentration compared to controls, while 
Table 1 Mean organ weight expressed as organ indices (\%) relative to body weights after 6 weeks of treatment

\begin{tabular}{lllll}
\hline Organs & \multicolumn{4}{l}{ Organ Weight Indices (\% bw) } \\
\cline { 2 - 5 } & $\mathbf{C o n}$ & $\mathbf{P b}$ & $\mathbf{P b}+$ Lip & Lip \\
\hline Heart & $0.4 \pm 0.04$ & $\mathbf{0 . 3 5} \pm \mathbf{0 . 0 1 *}$ & $0.35 \pm 0.02$ & $0.38 \pm 0.01$ \\
Liver & $2.95 \pm 0.09$ & $\mathbf{3 . 4 5} \pm \mathbf{0 . 1 6 *}$ & $2.88 \pm 0.05$ & $3.10 \pm 0.12$ \\
Spleen & $0.17 \pm 0.01$ & $\mathbf{0 . 2 1} \pm \mathbf{0 . 0 0 * *}$ & $0.19 \pm 0.01$ & $\mathbf{0 . 2 2} \pm \mathbf{0 . 0 1 * *}$ \\
Kidneys & $0.71 \pm 0.03$ & $0.68 \pm 0.03$ & $0.73 \pm 0.03$ & $0.66 \pm 0.02$ \\
Brain & $0.57 \pm 0.04$ & $\mathbf{0 . 4 6} \pm \mathbf{0 . 0 4 *}$ & $0.52 \pm 0.14$ & $0.53 \pm 0.02$ \\
\hline
\end{tabular}

Data are expressed as mean \pm SEM. SEM: Standard error of the mean; Con $=$ control; $\mathrm{Pb}=$ lead acetate; $\mathrm{Pb}+$ Lip $=$ lead acetate + L. javanica tea infusion; Lip $=$ L. javanica tea infusion. ${ }^{*} p<0.05 ;{ }^{* *} p<0.01$ compared to Con.

$\mathrm{Pb}+$ L. javanica and L. javanica treatment groups showed reduced MDA level $(p<0.05)$ compared to the control. Results are summarised in Table 2.

\section{Effect of Lippia javanica on brain acetylcholinesterase activity}

Exposure to $\mathrm{Pb}$ resulted in increased $\mathrm{AChE}$ activity $(p<0.01)$ compared to control. This effect was mitigated by treatment with $L$. javanica which resulted in decreased AChE activity to levels similar with control group and lower than $\mathrm{Pb}$ group $(p<0.05)$. Treatment with $L$. javanica alone also reduced AChE activity compared to the $\mathrm{Pb}$ exposed group $(p<0.001)$ (Fig. 1).

\section{Effect of Lippia javanica on brain inflammation and apoptosis}

Pro-inflammatory cytokine, TNF- $\alpha$ was highest in the $\mathrm{Pb}$ exposed group and was significantly higher $(p<0.001)$ than the control as well as the other treatment groups. Treatment with L. javanica partially reversed the $\mathrm{Pb}$ effects by reducing brain TNF- $\alpha$ concentrations compared to $\mathrm{Pb}$ group $(p<0.001)$ but remained higher $(p<0.01)$ compared to controls. Rats

Table 2 Antioxidant status of brain tissue

\begin{tabular}{lllll}
\hline Parameter & \multicolumn{4}{l}{ Treatment Groups } \\
\cline { 2 - 5 } & Con & Pb & Pb + Lip & Lip \\
\hline TAC $(\mathrm{mg} / \mathrm{mlTE})$ & $3.73 \pm 0.0$ & $3.57 \pm 0.1$ & $3.66 \pm 0.0$ & $3.62 \pm 0.1$ \\
GSH $(\mu \mathrm{Mol} / \mathrm{g}$ & $67.4 \pm 1.8$ & $57.1 \pm 2.8^{*}$ & $63.2 \pm 1.5^{\# \#}$ & $75.8 \pm 2.3^{\# \# \#}$ \\
tissue $)$ & & & & \\
$\mathrm{SOD}(\mathrm{U} / \mathrm{mL})$ & $16.2 \pm 1.1$ & $20.2 \pm 1.4^{*}$ & $20.6 \pm 1.3^{*}$ & $20.6 \pm 1.5^{*}$ \\
MDA $(\mu \mathrm{Mol} / \mathrm{L})$ & $3.81 \pm 0.7$ & $7.76 \pm 0.5^{*}$ & $6.17 \pm 0.2$ & $4.67 \pm 1.4$ \\
\hline
\end{tabular}

Data was expressed as mean \pm SEM

S.E.M Standard error of the mean, TAC Total antioxidant capacity, GSH Reduced glutathione, SOD Superoxide dismutase activity, MDA Malondialdehyde, Con control, $\mathrm{Pb}$ lead acetate, $\mathrm{Pb}+$ Lip lead acetate + L. javanica tea infusion, $\mathrm{Lip}$ L. javanica tea infusion

${ }^{*} p<0.05$ compared to Con; ${ }^{\# \#} p<0.01,{ }^{\# \# \#} p<0.001$ compared to $\mathrm{Pb}$.

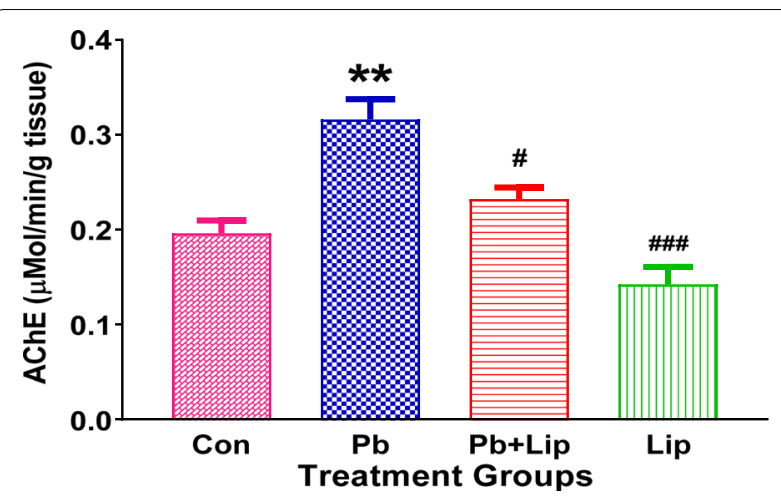

Fig. 1 Effect of L. javanica treatment on acetylcholinesterase (AChE) activity in brain. Data was expressed as mean \pm SEM. S.E.M: Standard error of the mean; Con = control; $\mathrm{Pb}=$ lead acetate; $\mathrm{Pb}+\mathrm{Lip}=$ lead acetate + L. javanica tea infusion; Lip $=$ L. javanica tea infusion; ${ }^{* *} p<0.01$ compared to Con; ${ }^{\#} p<0.05,{ }^{\# \# \#} p<0.001$ compared to $\mathrm{Pb}$

treated with L. javanica alone were similar to controls (Fig. 2A). Observations on the pro-apoptosis protein Bax were similar to those for TNF- $\alpha$ except that the $\mathrm{Pb}+$ L. javanica showed Bax levels lower than $\mathrm{Pb}$ group and similar to control. (Fig. 2B).

\section{Histological effects of Lippia javanica herbal tea}

Histological study of the hippocampus from the control and L. javanica treated groups showed normal hippocampal structure with pyramidal cells arranged neatly and tightly with no noticeable vacuolation or oedema (Fig. 3A \& B). However, the Pb exposed group showed severe vacuolation and oedema in the hippocampus, consistent with inflammation and cellular damage. Pyknotic nuclei are evident around areas of vacuolation (Fig. 3C). L. javanica treatment resulted in a clear improvement of $\mathrm{Pb}$-induced hippocampal damage with less vacuolization and oedema presenting neuroprotective effects (Fig. 3D).

\section{Phytochemicals present in Lippia javanica revealed by LC-MS}

L. javanica was shown to be rich in phenolics including syringaldehyde, protocatechuic acid, trans-cinnamic acid, syringic acid, caffeic acid, $p$-coumaric acid, ferulic acid, gallic acid and vanillic acid as shown in Table 1. The relative abundance in increasing order is as follows: vanillic acid $(10.87 \%)$, > caffeic acid (14\%), > p-coumaric acid (16.65), > protocatechuic acid (21\%), > syringic acid (25.34\%) with these five phenolics accounting for up to $88 \%$ of total phenolics identified in L. javanica (Table 3). 


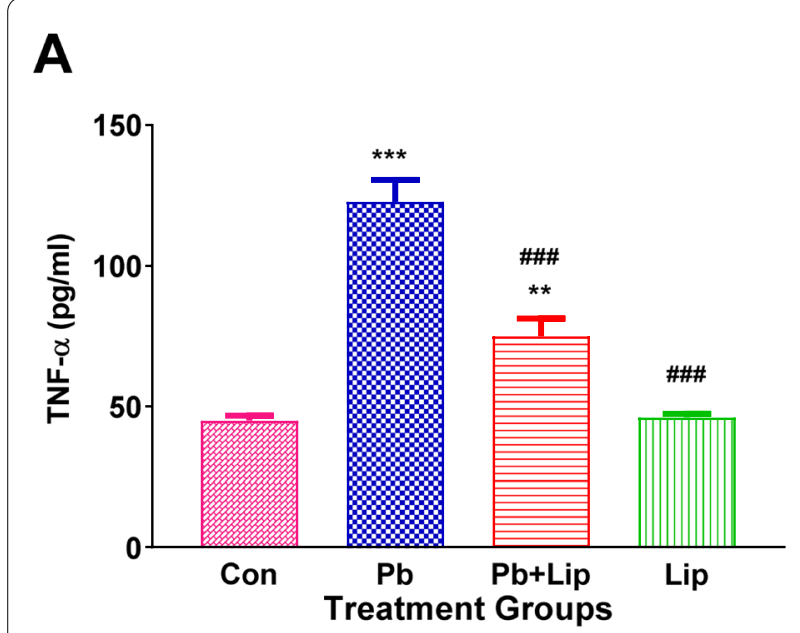

\section{B}

Fig. 2 Effect of L.javanica treatment on pro-inflammatory cytokine TNF-a $(\mathbf{A})$ and pro-apoptosis protein Bax (B) in brain tissue. Data was expressed as mean \pm SEM. S.E.M: Standard error of the mean; Con = control; $\mathrm{Pb}=$ lead acetate; $\mathrm{Pb}+\mathrm{Lip}=$ lead acetate + L. javanica tea infusion; $\mathrm{Lip}=\mathrm{L}$. javanica tea infusion; ${ }^{* *} p<0.01 ;{ }^{* * *} p<0.001$ compared to Con; ${ }^{\# \#} p<0.001$ compared to $\mathrm{Pb}$

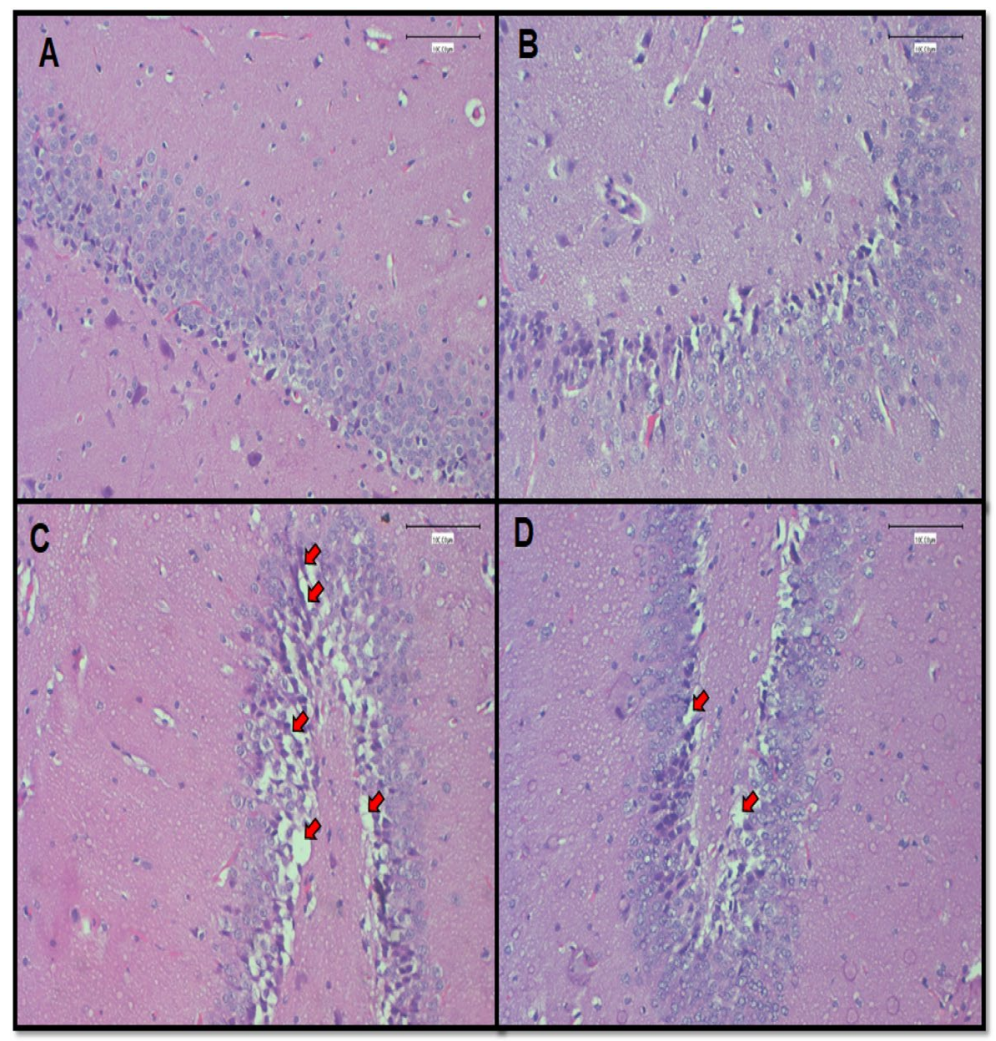

Fig. 3 Photomicrographs of rat hippocampus sections H\&E stained observed at $\times 20$ magnification. Ruler bar $=100 \mu \mathrm{m}$. Arrows indicate vacuolation and oedema. $\mathbf{A}=$ Control; $\mathbf{B}=$ L. javanica; $\mathbf{C}=$ lead acetate; $\mathbf{D}=$ lead acetate + L. javanica 
Table 3 Chemical composition of Lippia javanica detected by LC-MS

\begin{tabular}{lll}
\hline Compound & Concentration $(\boldsymbol{\mu g} / \mathbf{L})$ & Abundance $(\%)$ \\
\hline Syringic acid & $334.40 \pm 24.2$ & 25.34 \\
Protocatechuic acid & $277.23 \pm 23.0$ & 21.00 \\
p-coumaric acid & $219.67 \pm 11.6$ & 16.65 \\
Caffeic acid & $184.20 \pm 8.5$ & 13.96 \\
Vanillic acid & $143.38 \pm 5.4$ & 10.87 \\
Trans-cinnamic acid & $64.27 \pm 5.3$ & 4.87 \\
Syringaldehyde & $41.73 \pm 2.9$ & 3.16 \\
Gallic acid & $27.66 \pm 1.3$ & 2.10 \\
Ferulic acid & $27.23 \pm 2.1$ & 2.06 \\
\hline
\end{tabular}

Values expressed as mean \pm standard error of mean, $n=3$

\section{Discussion}

$\mathrm{Pb}$-induced toxicity, particularly neurotoxicity is known to be mediated through impairment of cholinesterase activity, generation of ROS as well as pro-inflammatory cytokines which can also generate ROS. L. javanica has been reported to possess antioxidant activity to scavenge ROS [24]. However, it remains unknown whether the $L$. javanica can promote neuroprotective effects through its antioxidant activity against $\mathrm{Pb}$-induced oxidative stress, inflammation, apoptosis and cholinesterase activity. This study was conducted to investigate the in vivo effects of Lippia javanica (Burm.f.) Spreng on Pb-induced brain oxidative stress and associated neurodegenerative effects.

$\mathrm{Pb}$ has the ability to cross the blood-brain barrier by competing with $\mathrm{Ca}^{2+}$ during neuronal firing and has been associated with neurodegenerative disorders [37]. It is well established that the neurodegenerative effects of $\mathrm{Pb}$ are linked to its role in causing oxidative stress $[1$, 6 , 27]. As such, studies have looked at combating brain oxidative stress and neurodegeneration with antioxidants [38]. Lippia javanica, a herbal tea plant whose antioxidant activity has been studied almost exclusively in vitro $[24,39]$, has not been investigated for antioxidant effects in vivo especially in the brain. To our knowledge, this is the first study to investigate effects of $L$. javanica on $\mathrm{Pb}$ induced brain damage. To achieve this, we exposed rats to $\mathrm{Pb}$ to induce damage and observed the effect on the animal's organs, paying attention to the brain which was our organ of interest. Brain weight was reduced as well as toxic effects on liver, heart and spleen were observed, and consistent with observations in previous studies attributed to $\mathrm{Pb}$-induced oxidative stress, inflammation, fibrosis and cell death [40].

The brain is highly susceptible to oxidative damage and lipid peroxidation due to its high oxygen requirements and high lipid content. The levels of glutathione and $\alpha$-tocopherol, both non-enzymatic antioxidants, are relatively low in the brain compared to the rest of the organs in the body [41]. Ingestion of plant-based antioxidants in the form of polyphenols may increase the brain's antioxidant capacity. Faria and colleagues [42] demonstrated that flavonoids are able to cross the blood-brain barrier and showed intact anthocyanins within various brain regions. In our study, the TEAC assay was used to measure the overall non-enzymatic antioxidant status in the brain, which included hydrophilic and lipophilic antioxidants as well as -sulfhydryl-containing antioxidants. $\mathrm{Pb}$ exposure had no effect on overall antioxidant status in the brain, nor $\operatorname{did} L$. javanica. However, glutathione was significantly increased in the L. javanica-treated $\mathrm{Pb}$ exposed animals compared to animals exposed to $\mathrm{Pb}$ only. These results suggest that though the total antioxidant level was same, $L$. javanica specifically increased glutathione level. Khalaf and colleagues [43] reported that $\mathrm{Pb}$ exposure at $100 \mathrm{mg} / \mathrm{kg} \mathrm{BW}$ resulted in lowered antioxidant status in the brain while green tea consumption at $5 \mathrm{~g} / \mathrm{L}$ ad libitum increased overall non-enzymatic antioxidant status in the brain, also using the TEAC assay.

SOD is an enzyme family that protects cells from the harmful effects of $\mathrm{O}^{2-}$ radical. In light of the brain's low, non-enzymatic antioxidant status, enzymatic antioxidants such as SOD are extremely important in protecting neurons against free radicals and oxidative stress. The SOD status in the brain was increased with $\mathrm{Pb}$ exposure, L. javanica consumption as well as with L. javanica-treated $\mathrm{Pb}$ exposure. This increased $\mathrm{SOD}$ activity may have a protective role in the cells of the brain which, in the case of $\mathrm{Pb}$ exposure, may be a protective response while the increase of SOD status may be due to upregulation by L. javanica treatment. Again, in parallel with our results, Reckziegel and colleagues [17] reported increased SOD status with $\mathrm{Pb}$ exposure as well as with gallic acid treatment.

Lipid peroxidation (LPO) can be defined as a free radical oxidation of polyunsaturated fatty acids [44]. LPO, as determined by MDA concentration, was increased in the $\mathrm{Pb}$ exposed group indicating that $\mathrm{Pb}$ exposure led to LPO in the brain as has previously been demonstrated [45]. On the other hand, though Pb-exposed $L$. javanica treatment group had increased LPO, it showed a trend towards a decrease compared to $\mathrm{Pb}$ exposure alone group $(p=0.1)$ indicating that $L$. javanica treatment prevented LPO to an extent. This was confirmed as treatment with $L$. javanica had no effect on LPO as the MDA level was similar to controls. Similarly, Reckziegel and colleagues reported that MDA concentration was increased with $\mathrm{Pb}$ exposure, but treatment of $\mathrm{Pb}$ exposure with gallic acid, a known flavonoid, reduced $\mathrm{Pb}$-induced LPO in the brain [17]. Also, curcumin has 
been shown to inhibit $\mathrm{Pb}$-induced oxidative stress and chelating activity [46].

$\mathrm{Pb}$ exposure has been suggested to promote inflammation. Generally, inflammatory cytokine expression is very low or undetectable in the brain under physiological conditions but tends to increase in conditions such as infections, trauma, autoimmune diseases or exposure to toxic agents [47]. $\mathrm{Pb}$ toxicity has been shown to induce increase level of pro-inflammatory cytokines such as IL-6, TGF- $\beta 1$ [11] and TNF- $\alpha$ [48]. Findings from this study showed that $\mathrm{Pb}$ induced inflammation as increased level of TNF- $\alpha$ was observed in Pb exposed animals but was reduced by $L$. javanica as the $\mathrm{Pb}$ exposed animals treated with $L$. javanica had a significantly lower TNF- $\alpha$ level. This finding confirms previous studies which have also shown some plants to prevent $\mathrm{Pb}$-induced inflammation [49]. $\mathrm{Pb}$ toxicity is known to promote apoptosis as it has been shown to increase the expression and synthesis of some pro-apoptotic proteins such as bcl-2 [14] and $\mathrm{Bax}$ proteins [50]. $\mathrm{Pb}$ induce the synthesis of $\mathrm{Bax}$ protein as it significantly increased in $\mathrm{Pb}$ exposed animals but was reduced by $L$. javanica treatment suggesting that $L$. javanica can prevent $\mathrm{Pb}$-induced apoptosis. $\mathrm{Pb}$ exposure has also been observed to affect neurotransmission. $\mathrm{Pb}$ has been shown to affect cholinergic systems in the hippocampus and septum impairing cholinergic nervous transmission [10]. Acetylcholinesterase regulates cholinergic neurotransmitters. Increased acetylcholinesterase activity impairs nervous transmission [11]. In this study, $\mathrm{Pb}$ exposed animals which were treated with $L$. javanica had a significantly reduced acetylcholinesterase level which was high in $\mathrm{Pb}$ exposed animals. Therefore, $L$. javanica treatment reduced cholinesterase activity which was induced by $\mathrm{Pb}$. This finding is consistent with previous studies which have also shown Thunbergia laurifolia (Linn.) [51] and propolis [52] to attenuate Pb-induced cholinesterase activities in animal models.

The hippocampus is a bilateral brain structure located in the temporal lobe on which learning and memory are critically dependant [53]. Episodic memory impairment is a hallmark of neurodegenerative diseases, such as Alzheimer's disease, which are neurobiologically linked to the hippocampus [54]. Liu and colleagues [48] reported that $\mathrm{Pb}$ exposure induced significant microgliosis and astrogliosis in hippocampus of young mice. In $\mathrm{Pb}$ treated rats, vacuolization and oedema was observed in the hippocampus area [43]. In our current study, $\mathrm{Pb}$ exposure caused severe hippocampal cellular damage which was similarly manifested as vacuolization and oedema. The hippocampal structure remained normal with $L$. javanica treatment, consistent with controls. The effects of $\mathrm{Pb}$ induced hippocampal damage were decreased with $L$. javanica, similar to previously published studies using green tea [43]. Thus, L. javanica protects against $\mathrm{Pb}$ induced neuronal damage.

To ascertain the phytochemicals in $L$. javanica that were responsible for the neuroprotective effects of $\mathrm{Pb}$ induced brain damage, LC-MS analysis was done. $L$. javanica was shown to be rich in phenolic acids among which vanillic acid, caffeic acid, $p$-coumaric acid, protocatechuic acid and syringic acid were high in abundance accounting for about $88 \%$ of the total phenolics while gallic acid, syringaldehyde, trans-cinnanic acid and ferulic acid were in small amounts. This finding confirms previous reports which have shown $L$. javanica to be rich in polyphenols such as flavonols flavonoids, and proanthocyanidin $[55,56]$. Most of these abundant phenolics compounds (syringic, $p$-coumaric, caffeic and vanillic acids) found in L. javanica have been reported in experimental models to possess anti-inflammatory and antioxidant activities [57-61] as well as anticholinesterase activity $[62,63]$ and in apoptosis in reducing the expression of Bcl [64]. This may suggest that the observed effects of $L$. javanica in this study may be accounted for by these phenolic compounds.

\section{Conclusions}

This study demonstrated that $L$. javanica possess a neuroprotective effect as it was effective in reducing $\mathrm{Pb}$ induced brain oxidative stress, inflammation, apoptosis, acetylcholinesterase activity and neuronal damage. Thus, L. javanica hearbal tea may be effective in preventing the onset of inflammation, apoptosis, oxidative stressinduced neurodegeneration, neuronal damage and its associated diseases.

\section{Abbreviations}

ABTS: 2, 2'-azino-bis-(3-ethylbenzthiazoline-6-sulphonic acid; AChE: Acetylcholinesterase; Bax: BCl-2 Associated X Protein; CAT: Catalase; CDC: Centers for Disease Control; CNS: Central nervous system; LC-MS: Liquid chromatographyMass spectrometer; GPX: Glutathione peroxidase; GR: Glutathione reductase; GSH: Glutathione; GSSG: Oxidised state; $\mathrm{H}_{2} \mathrm{O}_{2}$ : Hydrogen peroxide; $\mathrm{HO}_{2}$ : Hydroperoxides; IL: Interleukin; LPO: Lipid peroxidation; MDA: Malondialdehyde; Pb: Lead; ROS: Reactive oxygen species; SOD: Superoxide dismutase; TAC :Total Antioxidant capacity; TBARS: Thiobarbituric acid reactive substances; TE: Trolox equivalent; TEAC: Trolox equivalent antioxidant capacity; TGF- $\beta 1$ : Transforming growth factor $\beta 1$; TNB: 5 - thionitrobenzoic acid; TNF-a: Tumour necrotic factor-a.

\section{Acknowledgements}

The authors are grateful to Walter Sisulu University for proving laboratory space to conduct this research.

\section{Authors' contributions}

"C.R.S.-R. developed the concept, designed and funded the study. H.T.M. and C.R.S.-R. were responsible for LC-MS and in vitro antioxidant analyses. C.R.S.-R., N.A.K. and Z.S. performed the animal study and ELISA. N.A.K. and M.S. performed cell counts and histology. Z.S., G.A.E., C.R.S.-R., H.T.M., N.A.K. and M.S. analysed and interpreted the data. G.A.E. and C.R.S.-R. wrote the manuscript and prepared all figures. All authors proofread and approved the final manuscript." 


\section{Funding}

The authors are thankful to the South African Medical Research Council (SAMRC) for the Self-Initiated Research Grant to the author of correspondence.

\section{Availability of data and materials}

All data generated or analysed during this study are included in this published article.

\section{Declarations}

\section{Ethics approval and consent to participate}

All methods were performed in accordance with the study protocol of relevant institutional, national, and international guidelines, regulations and legislation" required for plant and animal studies. This study was conducted in accordance with the ethical guidelines of Animal Care and Use and the Animal Research: Reporting of In Vivo Experiments (ARRIVE) guidelines. Ethics clearance for this study was obtained from Faculty of Health Sciences Research Ethics Committee, Walter Sisulu University (WSU), South Africa with ethics clearance reference number: 060/2016. This is an animal study so no consent to participate was required.

\section{Consent for publication}

Not applicable.

\section{Competing interests}

The authors declare that they have no competing interests.

\section{Author details}

${ }^{1}$ Department of Human Biology, Faculty of Health Sciences, Walter Sisulu University PBX1, Mthatha 5117, South Africa. ${ }^{2}$ Department of Biological and Environmental Sciences, Faculty of Natural Sciences, Walter Sisulu University PBX1, Mthatha 5117, South Africa.

Received: 14 September 2021 Accepted: 30 November 2021

Published online: 04 January 2022

\section{References}

1. Ye F, Li X, Li L, Lyu L, Yuan J, Chen J. The role of Nrf2 in protection against $\mathrm{Pb}$-induced oxidative stress and apoptosis in SH-SY5Y cells. Food Chem Toxicol. 2015;86:191-201.

2. Mathee A, Röllin H, von Schirnding Y, Levin J, Naik I. Reductions in blood lead levels among school children following the introduction of unleaded petrol in South Africa. Env Res. 2006;100:319-22.

3. Debnath B, Singh WS, Manna K. Sources and toxicological effects of lead on human health. Indian J Med Spec. 2019;10:66-71.

4. Giel-Pietraszuk M, Hybza K, Chełchowska M, Barciszewski J. Mechanisms of lead toxicity. Adv Cell Biol. 2012;39:17-248.

5. Amadi CN, lgweze ZN, Orisakwe OE. Heavy metals in miscarriages and stillbirths in developing nations. Middle East Fertil Soc J. 2017;22:91-100.

6. Lamidi IY, Akefe IO. Mitigate effects of antioxidants in Lead toxicity. Clin Pharmacol Toxi J. 2017:1:3.

7. Ahmed MB, Ahmed MI, Meki AR, Abdraboh N. Neurotoxic effect of lead on rats: relationship to apoptosis. Int J Health Sci Qassim University. 2013;7:192-9.

8. Flora G, Gupta D, Tiwari A. Toxicity of lead: a review with recent updates. Interdiscip Toxicol. 2012;5:47-58.

9. Lyn P. Lead toxicity, a review of the literature. Part I: exposure, evaluation, and treatment. Altern Med Rev. 2006;11:2-22.

10. Jankowska-Kulawy A, Gul-Hinc S, Bielarczy H, Suszkiw JB, PawełczykT, Dyś A, et al. Effects of lead on cholinergic SN56 neuroblastoma cells. Acta Neurobiol Exp. 2008;68:453-62.

11. Lane RM, Potkin SG, Enz A. Targeting acetylcholinesterase and butyrylcholinesterase in dementia. Int J Neuropsychopharmacol. 2006;9:101-24.

12. Chibowska K, Baranowska-Bosiacka I, Falkowska A, Gutowska I, Goschorska M, Chlubek D. Effect of Lead (Pb) on inflammatory processes in the brain. Int J Mol Sci. 2016;17:2140.
13. Dribben WH, Creeley CEN. Low-level lead exposure triggers neuronal apoptosis in the developing mouse brain. Neurotoxicol Teratol. 2011;33:473-80.

14. Sharifi AM, Mousavi SH, Jorjani M. Effect of chronic Lead exposure on pro-apoptotic Bax and anti-apoptotic Bcl-2 protein expression in rat Hippocampus in vivo. Cell Mol Neurobiol. 2010;30:769-74.

15. Lopes ACA, Peixe TS, Mesas AE, Paoliello MMB. Lead exposure and oxidative stress: a systematic review. Rev Env Contamination Toxicol. 2016;236:196-234.

16. Sidhu P, Nehru B. Lead intoxication: histological and oxidative damage in rat cerebrum and cerebellum. J Trace Elements Exp Med. 2004;17:45-53.

17. Reckziegel P, Dias VT, Benvegnú D, Boufleur N, Barcelos RCS, Segat HJ, et al. Locomotor damage and brain oxidative stress induced by lead exposures are attenuated by gallic acid treatment. Toxicol Letters. 2011;203:74-81.

18. Su P, Zhang J, Wang S, Aschner M, Cao Z, Zhao F, et al. Geinstein alleviates lead-induced neurotoxicity in vitro and in vivo: involvement of multiple signalling pathways. Neurotoxicol. 2016;53:153-64.

19. Bhebhe M, Chipurura B, Muchuweti M. (). Determination and comparison of phenolic compound content and antioxidant activity of selected local Zimbabwean herbal teas with exotic Aspalathus linearis. S African J Bot. 2015;100:213-8.

20. Katerere DR, Graziani G, Thembo KM, Nyazema NZ, Ritieni A. Antioxidant activity of some African medicinal and dietary leafy African vegetables. African J Biotechnol. 2012;11(17):4103-8.

21. Shikanga EA, Combrinck S, Regnier T. South African Lippia herbal infusions: Total phenolic content, antioxidant and antibacterial activities. S Afr J Bot. 2010;76:567-71.

22. York T, De Wet H, Van Vuuren SF. Plants used for treating respiratory infections in rural Maputaland, KwaZulu-Natal, S Africa. J Ethnopharmacol. 2011;135:696-710.

23. Maroyi A. Lippia javanica (Burm. F.) Spreng.: traditional and commercial uses and phytochemical and pharmacological significance in the african and indian subcontinent. Evid based Compl Alter Med. 2017;2017:6746071.

24. Suleman Z. Comparing the antioxidant properties of Lippia javanica with Aspalathus linearis (rooibos), BSc III research assignment (Unpublished); 2015.

25. von Gadouw A, Joubert E, Hansmann CF. Comparison of the antioxidant activity of rooibos tea (Aspalathus linearis) with green, oolong and black tea. Food Chem. 1997;60:73-7.

26. South African National Standard: the care and use of animals for scientific purposes. 2008. (SANS10386: 2008). Published by SABS Standards Division, Pretoria South Africa.

27. Nehru B, Sidhu P. Behaviour and neurotoxic consequences of lead on rat brain followed by recovery. Biol Trace Element Res. 2001;84:113-21.

28. CCOHS. Chemicals and materials fact sheet. Canadian Centre for. Occup Health Saf. 2018; Accessed 18th of April 2020. https://www.ccohs.ca/ oshanswers/chemicals/ld50.html.

29. Joubert E, Gelderblom WCA, Louw A, de Beer D. South African herbal teas: Aspalathus linearis, Cyclopia spp. and Athrixia phylicoides - a review. J Ethnopharmacol. 2008;119:376-412.

30. Arnao MB, Cano A, Acosta M. The hydrophilic and lipophilic contribution to total antioxidant capacity. Food Chem. 2001;73:239-44.

31. Owens CWI, Belcher RV. A colorimetric micro-method for the determination of glutathione. Biochem J. 1965;94:705.

32. Mallick M, Mandal S, Barik B, Bhattacharya A, Ghosh D. Protection of testicular dysfunctions by MTEC, a formulated herbal drug, in streptozotocin induced diabetic rat. Biol Pharm Bull. 2007;30:84-90.

33. Ellman GL, Courtney KD, Andres V Jr, Featherstone RM. A new and rapid colorimetric determination of acetylcholinesterase activity. Biochem Pharmacol. 1961:7:88-95.

34. Tiya S, Sewani-Rusike CR, Shauli M. Effects of treatment with Hypoxis hemerocallidea extract on sexual behaviour and reproductive parameters in male rats. Andrologia. 2017;49:e12742.

35. Mfengu MOM, Shauli M, Engwa GA, Musarurwa HT, Sewani-Rusike CR. Lippia javanica (Zumbani) herbal tea infusion attenuates allergic airway inflammation via inhibition of Th2 cell activation and suppression of oxidative stress. BMC Complement Med Ther. 2021;21(1):192.

36. Rautenbach M, Vlok NM, Eyéghé-Bickong HA, van der Merwe MJ, Stander MA. An electrospray ionization mass spectrometry study on the "in Vacuo" 
hetero-oligomers formed by the antimicrobial peptides, surfactin and gramicidin. S J Am Soc Mass Spectrometry. 2017;28(8):1623-37.

37. Serlin Y, Shelef L, Knyazer B, Friedman A. Anatomy and physiology of the blood-brain barrier. Seminars Cell Developmental Biol. 2015;38:2-6.

38. Su P, Zhang J, Wang S, Aschner M, Cao Z, Zhao F, et al. Geinstein alleviates lead-induced neurotoxicity in vitro and in vivo: involvement of multiple signalling pathways. Neurotoxicol. 2016;53:153-64.

39. Shikanga EA, Combrinck S, Regnier T. South African Lippia herbal infusions: Total phenolic content, antioxidant and antibacterial activities. South Afr J Bot. 2010;76:567-71.

40. Elaga MK, Daughtry LK, Jones AC, Yallapragada PR, Rajanna S, Rajanna B. Attenuation of lead-induced oxidative stress in rat brain, liver, kidney and blood of male Wistar rats by Moringa oleifera seed powder. J Env Pathol Toxicol Oncol. 2014;33:323-37.

41. Ohta Y, Yashiro k, Ohashi k, Imai Y. Disruption of non-enzymatic antioxidant defense systems in the brain of rats with water-immersion restraint stress. J Clin Biochem Nut. 2012;51:136-42.

42. Faria A, Mateus N, Calhau C. Flavonoid transport across the blood-brain barrier: implication for their direct neuroprotective actions. Nut Aging. 2012;1:89-97.

43. Khalaf AA, Moselhy WA, Abdel-Hamed MI. The protective effect of green tea extract on lead induced oxidative and DNA damage on rat brain. Neurotoxicol. 2012;33:280-9.

44. Nam T. Lipid peroxidation and its toxicological implications. Official J Kor Soc Toxicol. 2011:27:1-6.

45. Prasanthi RPJ, Devi CB, Basha DC, Reddy NS, Reddy GR. Calcium and zinc supplementation protects lead ( $\mathrm{Pb}$ )-induced perturbations in antioxidant enzymes and lipid peroxidation in developing mouse brain. Int J Developmental Neurosci. 2010;28:161-7.

46. Abubakar K, Mailafiya MM, Danmaigoro A, Chiroma SM, Rahim EBA, Zakaria MZAB. Curcumin attenuates Lead-induced cerebellar toxicity in rats via chelating activity and inhibition of oxidative stress. Biomolecules. 2019;9:453.

47. Oprica M, Eriksson C, Schulzberg M. Inflammatory mechanisms associated with brain damage induced by kainic acid with special reference to the intereukin-1 system. J Cell Mol Med. 2003;7:127-40.

48. Liu J-T, Chen B-Y, Zhang J-Q, Kuang F, Chen L-W. Lead exposure induced microgliosis and astrogliosis in hippocampus of young mice potentially by triggering TLR4-MyD88-NFKB signaling cascades. Toxicol Letters. 2015;239:97-107.

49. Farag MR, Alagawany M, Abd El-Hack ME, El-Sayed SAA, Ahmed SYA, Samak DH. Yucca schidigera extract modulates the lead-induced oxidative damage, nephropathy and altered inflammatory response and glucose homeostasis in Japanese quails. Ecotoxicol Env Safety. 2018;156:311-21.

50. Niu Y, Zhang R, Cheng Y, Sun X, Tian J. Effect of lead acetate on the apoptosis and the expression of and bax genes in rat brain cells. Chin J Prev Med. 2002;36:30-3.

51. Phyu MP, Tangpong J. Protective effect of Thunbergia laurifolia (Linn.) on Lead induced acetylcholinesterase dysfunction and cognitive impairment in mice. Biomed Res Int. 2013;2013:186098. https://doi.org/10.1155/ 2013/186098

52. El-Masry TA, Emara AM, El-Shitany NA. Possible protective effect of propolis against lead induced neurotoxicity in animal model. J Evol Biol Res. 2011:3:4-11.

53. Kubo K, Murabayashi C, Kotachi M, Suzuki A, Mori D, Sato Y, et al. Tooth loss early in life suppresses neurogenesis and synaptophysin expression in the hippocampus and impairs learning in mice. Arch Oral Biol. 2016;74:21-7

54. Greenbaum L, Ravona-Springer R, Lubitz I, Schmeidler J, Cooper I, Sano $\mathrm{M}$, et al. Potential contribution of the Alzheimer's disease risk locus BIN1 to episodic memory performance in cognitively normal type 2 diabetes elderly. Eur Neuropsychopharmacol. 2016;26:787-95.

55. Shikanga EA, Combrinck S, Regnier T. South African Lippia herbal infusions: Total phenolic content, antioxidant and antibacterial activities. S Afr J Bot. 2010;76(3):567-71.

56. Asowata-Ayodele AM, Otunola GA, Afolayan AJ. Assessment of the polyphenolic content, free radical scavenging, anti-inflammatory, and antimicrobial activities of acetone and aqueous extracts of Lippia javanica (Burm.F.) spreng. Pharmacog Mag. 2016;3:353-62.
57. Srinivasulu C, Ramgopal M, Ramanjaneyulu G, Anuradha CM, Kumar CS. Syringic acid (SA)-a review of its occurrence, biosynthesis, pharmacological and industrial importance. Biomed Pharmacother. 2018;108:547-57.

58. Pei K, Ou J, Huang J, Ou S. P-Coumaric acid and its conjugates: dietary sources, pharmacokinetic properties and biological activities. J Sci Food Agriculture. 2016;96(9):2952-62.

59. Pragasam SJ, Venkatesan V, Rasool M. Immunomodulatory and antiinflammatory effect of $\mathrm{p}$-coumaric acid, a common dietary polyphenol on experimental inflammation in rats. Inflammation. 2013;36(1):169-76.

60. Paciello F, Di Pino A, Rolesi R, Troiani D, Paludetti G, Grassi C, et al. Anti-oxidant and anti-inflammatory effects of caffeic acid: in vivo evidences in a model of noise-induced hearing loss. Food ChemToxicol. 2020;143:111555.

61. Calixto-Campos C, Carvalho TT, Hohmann MS, Pinho-Ribeiro FA, Fattori V, Manchope MF, et al. Vanillic acid inhibits inflammatory pain by inhibiting neutrophil recruitment, oxidative stress, cytokine production, and NFkB activation in mice. J Natural Products. 2015;78(8):1799-808.

62. Szwajgier D. Anticholinesterase activities of selected polyphenols - a short report. Polish J Food Nutr Sci. 2014;64(1):59-64.

63. Mangmool S, Kunpukpong I, Kitphati W, Anantachoke N. Antioxidant and anticholinesterase activities of extracts and phytochemicals of Syzygium antisepticum leaves. Molecules. 2021;26:3295.

64. Han DH, Jeong JH, Kim JH. Anti-proliferative and apoptosis induction activity of green tea polyphenols on human Promyelocytic leukemia HL-60 cells. Anticancer Res. 2009;29:1417-22.

\section{Publisher's Note}

Springer Nature remains neutral with regard to jurisdictional claims in published maps and institutional affiliations.

Ready to submit your research? Choose BMC and benefit from

- fast, convenient online submission

- thorough peer review by experienced researchers in your field

- rapid publication on acceptance

- support for research data, including large and complex data types

- gold Open Access which fosters wider collaboration and increased citations

- maximum visibility for your research: over $100 \mathrm{M}$ website views per year

At BMC, research is always in progress.

Learn more biomedcentral.com/submissions 